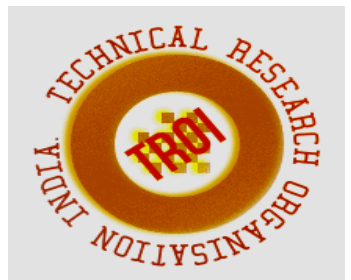

\title{
DESIGN AND DEVELOPMENT OF ENERGY EFFICIENT DOMESTIC WATER HEATER USING SMART MATERIALS
}

\author{
Rahul basappa hadapad ${ }^{\mathbf{1}}$, Dr. H. Ghanashyam Shenoy ${ }^{2}$, Pruthvi $\mathrm{H} \mathrm{M}^{3}$, Sagar S. ${ }^{4}$ \\ ${ }^{1,2,3,4}$ Department of Mechanical Engineering, Dr. T. Thimmaiah Institute of Technology, Kolar \\ Gold Fields-563120, Karnataka, India
}

\begin{abstract}
In the present era, a large amount of energy is being consumed in the field of domestic water heaters, especially in the cold countries. It has been found that very less research has been done in this field so as to provide an energy efficient domestic water heater by replacing the Poly-Urethane foam using smart materials. It works by optimizing the Efficiency of Heat Dissipation by Phase Transformation and minimizing the power consumption. In the present research, the conventional water heater has been modified with the outer shell made up of aluminum where in the smart material mix is filled and this is used to supply the required heat to heat the water. The water heater with modification has been tested successful where a larger amount of water was able to be heated up to the same temperature using the same amount of power thereby increasing its efficiency.

Keywords: phase transformation, foam, heat dissipation.
\end{abstract}

\section{INTRODUCTION}

In the recent years the interest in metallic foam has increased considerably. Natively existing porous materials with higher stiffness and low specific weight exist and these examples prompted the development of artificial cellular materials made from polymers, ceramics and glass. It therefore seemed reasonable to make a cellular material out of metals since if this would be possible such foam could offer interesting perspectives due to the combination of the metallic properties and the special features of the foam.

In the last 40 years many attempts have been made to produce metallic foam structures, they were not successful, because of their relatively high costs. Furthermore, it was not possible to produce metallic foam with reproducible properties. Problems occurred with a low formability of the molten metal, the varying size of cellular structures or solidification shrinkage. However, recently these issues have been solved by extensive research that has lead to the development of new production technologies. These new foaming technologies allow the production of foam of a significant higher quality. In particular the foaming of aluminium was successful.

Demand water heaters are those that can be placed centrally like storage water heaters, or designed specifically to be placed near the pointof-use. The demand water heater, despite providing energy and water saving advantages over the geyser, is usually only suitable as a supplementary device to a geyser, or as a replacement under suitable conditions.

However, Henze, Yuill and Coward, Johnson and Clark and Wiehagen and Sikora agree that demand water heaters placed at the point-of-use are likely to provide opportunities for improved thermal and electrical efficiency. The agreement between these authors leads this study to move away from geysers and focus on developing the demand water heating concept. Unlike geysers, demand water heaters do not keep a full tank of water heated continuously at a pre-set temperature, so by comparison, they use no electricity when idle. Demand water heaters waste less water than geysers do as they are usually placed close to, or at the tap. Geysers promote significant heat loss in comparison to demand water heaters. Since geysers depend on the piping of heated water from the centralized geyser to the tap, significant heat losses occur in the pipes as a result of conduction and convection. Geyser, to a very small extent demand water heaters, waste additional energy 
by elevating the water temperature in the tank to compensate for piping thermal losses.

\section{METHODOLOGY}

A. The embedded experimental model variant of mixed-methods research is used as the basis for this study. In this study, we first collect and analyze the quantitative data that measures the heating chamber performance. The heating chamber is then fitted with an outer shell having a clearance of $1 \mathrm{~cm}$ and the space between is filled with the smart material mixture (Aluminium $6063+$ zirconium + nitinol tini ). Thus when heat is supplied to the smart material mixture, the blasting of aluminium takes place which is an exothermic process, where the aluminium atoms open up and the air fills the spaces in between, hence releasing a huge amount of energy. This energy is used to heat the water in the heating chamber. Thus when the heat from the smart material mixture is fully dissipated to the water, the decomposition of aluminium foam takes place and it is converted back to aluminium, and the process is repeated. The rationale for this methodological approach is that the study of device performance and user behavior provides a broader and deeper understanding of how to save water and electricity as both contribute to the efficiency of water heating.

\section{DESIGN OF DEMAND WATER HEATER}

The conventional water heater is fitted with an outer shell made of aluminium made by the conventional metal spinning process. This outer shell around the water heater is used for filling the smart material mixture of Aluminium $6063+$ zirconium + nickel. Thus when the current is passed through the coil, this heats the water and also the shell surrounding it. Thus when the shell gets heated up, it acts as a heat exchanger where in the heat from the outer shell is transferred to the water in the inner shell thereby heating it.

Table 1: Dimensions of outer shell

\begin{tabular}{|l|c|}
\hline Design parameters & Dimensions in mm \\
\hline Diameter & 120 \\
\hline Length & 200 \\
\hline Thickness & 3 \\
\hline
\end{tabular}

\section{TABLE 2: SPECIFICATIONS OF ORIGINAL WATER HEATER}

\begin{tabular}{|c|c|}
\hline $\begin{array}{c}\text { Specifications of } \\
\text { original water heater }\end{array}$ & Description \\
\hline Capacity & 1 litr. \\
\hline Mounting & Vertical \\
\hline Outer body & ABS \\
\hline Inner tank & Stainless steel \\
\hline Power supply & $230 \mathrm{VAC}$ \\
\hline Rated power & $3 \mathrm{KW}$ \\
\hline Thermostat & Stem type ISI mark \\
\hline Working pressure & $3-3.5$ bar \\
\hline Element & $\begin{array}{c}\text { Long lasting specially designed copper tube } \\
\text { tubular heating element }\end{array}$ \\
\hline
\end{tabular}
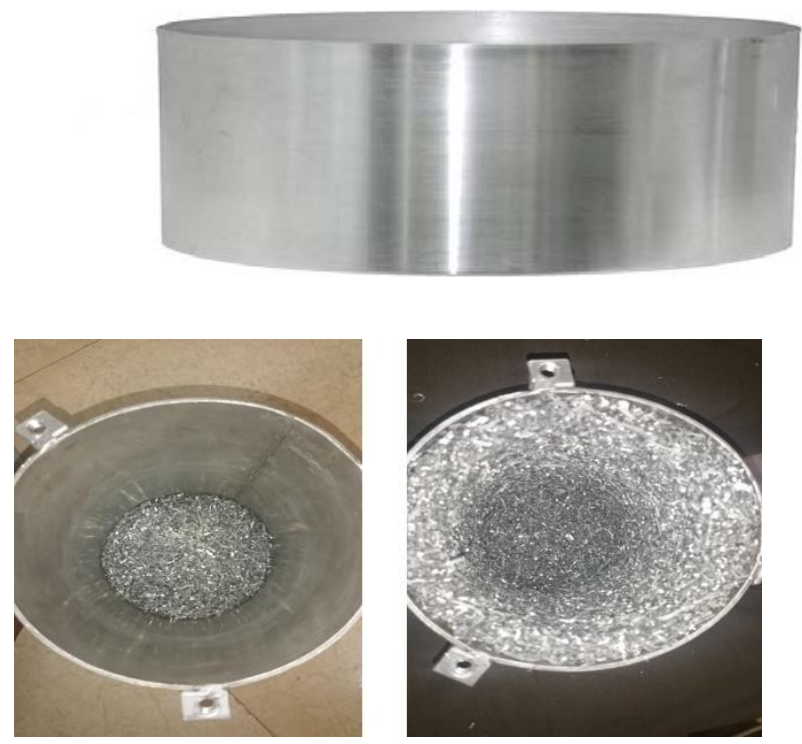

Figure 1outer shell

Fig 2: Aluminum and Zirconium In outer Shell

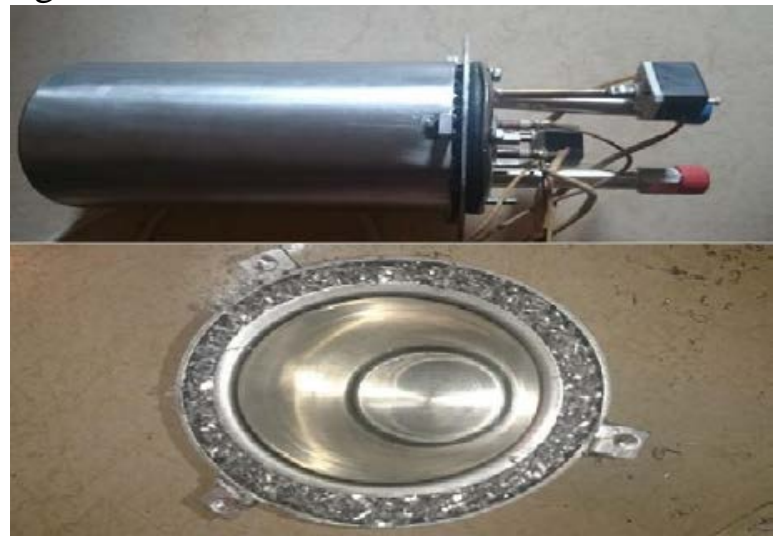

Figure 3 Water heater with modification 


\section{RESULTS AND DISCUSSION}

\begin{tabular}{|c|l|}
\hline \multicolumn{1}{|c|}{$\begin{array}{c}\text { Case 1 } \\
\text { Normal Water Heater }\end{array}$} & \multicolumn{1}{c|}{$\begin{array}{c}\text { Case 2 } \\
\text { Water Heater with Modification }\end{array}$} \\
\hline $\begin{array}{l}\text { To heat } 1 \text { litre water } 5 \text { minutes } \\
\text { Power consumed 3200 Watts 13 A }\end{array}$ & $\begin{array}{l}\text { Same power supplied for 5 minutes } \\
\text { Amount of water heated to same } \\
\text { temperature }-1.5 \text { litre approx. }\end{array}$ \\
\hline
\end{tabular}

\section{CONCLUSION}

The water heater with modification has been tested successful where a larger amount of water was able to be heated up to the same temperature using the same amount of power thereby increasing its efficiency. The applications can be wide and within the cost reachable to the middle man.

\section{SCOPE OF FUTURE WORK}

A heating coil is to be wound in the shell area of the filling so as to raise the temperature of the filling to about 300 degrees in a much faster way thereby increasing its efficiency. Here the heating coil fills the shell area in which the smart material filling is placed. So when the smart material filling is added, the heating coil will be surrounded by the smart material filling on all sides. Thus when current is passed through the heating coil, the coil gets heated wherein the heat from the coil is transmitted to the smart materials, thereby heating the outer shell. This helps in heating the water in the inner container.

\section{REFERENCES}

[1].Duarte, J. Banhart., A study of aluminium foamformation - kinetics and microstructure. Acta Materialia 48(9), 2349-2362 (2000).

[2].Hakon Hallem., Precipitation behavior and recrystallisation resistance in aluminium alloys with additions of hafnium, scandium and zirconium An experimental investigation., 2005

[3].Eunji Hong, David C. Dunand, Heeman Choe, Hydrogen- induced transformation superplasticity in zirconium. Evanston IL 60208, USA.

[4].LI Da-wu, LI Jie1, LI Tao, SUN Ting, ZHANG Xiao- ming, YAO Guang-chun, Preparation and characterization of aluminum foams with $\mathrm{ZrH} 2$ as foaming agent, Nonferrous Met. Soc. China 21(2011) 346-352.

[5]. Young-Min Kong, Hyoun-Ee Kim and Hae-Won Kim, Production of AluminumZirconium Oxide Hybridized Nanopowder and Its Nanocomposite, J. Am. Ceram. Soc., 90 [1] 298-302 (2007).

[6].B. Matijasevic-Lux J. Banhart S. Fiechter O. G“orke N. Wanderka, Modification of titanium hydride for improved aluminium foam manufacture, Acta Materialia 54(7), 1887-1900 (2006).

[7].John Banhart, Manufacture, characterisation and application of cellular metals and metal foams. Progress in Materials Science 46 (2001) 559-632.

[8].Biljana Matijasevic, Oliver Gorke , Helm ut Schubert, John Banhart,Zirconium Hydride-a Possible Blowing Agent for Making Aluminium Alloy Foams, MetFoam2005 I $\quad$ JIMIC-4 